\title{
Intra-arterial chemotherapy improved survival of stage 2-3 gallbladder cancer after curative resection
}

This article was published in the following Dove Press journal:

OncoTargets and Therapy

\section{Cheng Chen' \\ Wenming Feng' \\ Yinyuan Zheng ${ }^{2}$ \\ Ying Bao' \\ Min Feng'}

'Department of General Surgery, First People's Hospital affiliated to Huzhou Normal College, Huzhou, Zhejiang

Province, People's Republic of China; ${ }^{2}$ Department of Radiology, First People's Hospital affiliated to Huzhou Normal College, Huzhou, Zhejiang Province, People's Republic of China
Correspondence: Min Feng Department of General Surgery, First People's Hospital affiliated to Huzhou Normal College, Huzhou, Zhejiang Province, 313000, People's Republic of China Tel +572 203936

Fax +5722023728

Email fengmin_dr@aliyun.com
Objective: To investigate the impact of postresection intra-arterial chemotherapy (IAC) on prognosis of stage 2-3 gallbladder cancer (GBC) after curative resection.

Methods: Between May 2010 and August 2014, 76 cases of GBC accepted curative surgery in our center and were pathologically staged as 2-3. After resection, 37 underwent 4 courses of intravenous chemotherapy (IVC) following 2 courses of IAC (ART group), and 39 received 6 courses of IVC (SYS group). Both the IAC and IVC regimens consisted of oxaliplatin $\left(85 \mathrm{mg} / \mathrm{m}^{2}\right)$ on day 1 and gemcitabine $\left(800 \mathrm{mg} / \mathrm{m}^{2}\right)$ on day 1 and day 8 . Chemotherapy-related complications, disease-free survival (DFS), overall survival (OS), and hepatic metastases-free survival (HMFS) were retrospectively analyzed.

Results: Patient characteristics and chemotherapy complications did not differ between the two groups. There was no significant difference in 3-year DFS of the two groups $(p=0.0822$, $\mathrm{HR}=0.6270 ; 95 \% \mathrm{CI}, 0.3627$ to 1.0838 ). The ART group had significantly higher 3-year OS $(p=0.0378, \mathrm{HR}=0.5460 ; 95 \% \mathrm{CI}, 0.3025$ to 0.9856$)$ and 3 -year HMFS $(p=0.0414, \mathrm{HR}=0.5187$; $95 \%$ CI, 0.2706 to 0.9940 ) than the SYS group.

Conclusions: IAC could effectively and safely decrease postresection hepatic metastases and improve 3-year HMFS and OS of stage 2-3 GBC.

Keywords: gallbladder cancer, intra-arterial chemotherapy, hepatic metastases, survival

\section{Introduction}

In spite of the advancement in chemotherapy and surgery, gallbladder cancer (GBC) remains a disease with an unfavorable survival and the 5-year overall survival (OS) ranges from $50 \%$ in stage 1 to $2 \%$ in metastatic disease. ${ }^{1}$ Surgery offers a chance of cure, but most patients experience a recurrence despite curative resection. ${ }^{2}$ Therefore, considerable interest exists in applying adjuvant therapy in resected GBC, although high-quality evidence supporting this practice is lacking and therapy largely relies on retrospective observational data. ${ }^{3}$

Chemotherapy is still one of the most commonly applied postoperative adjuvant therapies for $\mathrm{GBC}$, but most of the chemotherapy regimes cannot offer a favorable survival benefit and usually cause serious side effects. ${ }^{4}$ Therefore, it is urgent to seek alternative adjuvant therapeutic methods. The liver is the most common site of recurrence after radical resection of GBC. ${ }^{5}$ We previously found that intra-arterial chemotherapy (IAC) could significantly decrease metachronous liver metastases from colorectal cancer and improve long-term survival. ${ }^{6}$ In this retrospective study, we aimed to figure out whether IAC could decrease hepatic recurrence and improve prognosis of stage 2-3 GBC after curative resection. 


\section{Method}

\section{Patients}

Between May 2010 and August 2014, 76 patients with GBC underwent curative surgery in our center and were pathologically staged as 2-3 according to American Joint Committee on Cancer guidelines, 7 th edition. $^{7}$ After resection, 37 underwent 4 courses of intravenous chemotherapy (IVC) following 2 courses of IAC (ART group), and 39 underwent 6 courses of IVC (SYS group). Criteria for enrollment were: histologically confirmed as stage 2-3 GBC, no previous anticancer treatment, Karnofsky performance score $\geq 70$, postoperative life span $>6$ months, sufficient liver, hematopoietic, and kidney function, and age from 18 to 75 . According to the patients' medical documents, the patient characteristics, chemotherapy-related complications, diseasefree survival (DFS), OS, and hepatic metastases-free survival (HMFS) were retrospectively analyzed. Patients selected their chemotherapy regime and signed a consent form after reading the instruction about each chemotherapy regime. This study obtained approval from the ethics committee of First People's Hospital affiliated to Huzhou Normal College.

\section{Chemotherapy administration}

Chemotherapy was initiated within 3 weeks after surgery and repeated every 28 days. Both the IAC and IVC regimens consisted of oxaliplatin $\left(85 \mathrm{mg} / \mathrm{m}^{2}\right)$ on day 1 and gemcitabine $\left(800 \mathrm{mg} / \mathrm{m}^{2}\right)$ on day 1 and day 8 .

IAC was administered using a micropump through a catheter of which the end was placed into the common hepatic artery or proper hepatic artery. ${ }^{8}$ At the end of the infusion, the catheter was removed. All patients were supervised and complications were appropriately treated. The severity of chemotherapy toxicities were assessed according to the National Cancer Institute Common Terminology Criteria for Adverse Events, version 4.0. ${ }^{9}$ Treatment was ceased if unacceptable toxicities occurred or on the patient's request.

\section{Follow-up}

All patients were followed up every month in the first postoperative year and every 3 months thereafter. Recurrence was diagnosed by enhanced computed tomography or magnetic resonance imaging and, if necessary, biopsy. Alternative chemotherapy regimens or palliative treatment were administered if recurrence was diagnosed.

\section{Statistical analysis}

All measurements were presented as mean \pm SD. Student's $t$-test, chi-square test, or Fisher's exact test was appropriately utilized to analyze the clinical data. Survival curves were calculated using the Kaplan-Meier method. The difference of the survival was evaluated using the log-rank test. All statistical analyses were carried out with statistical software package SPSS for Windows (version 17.0; SPSS Inc., Chicago, IL, USA). $p<0.05$ was considered significant.

\section{Results}

\section{Patient characteristics}

Table 1 shows that patient characteristics did not differ between the 2 groups, such as age, tumor size, blood loss during surgery, level of carbohydrate antigen 19-9, gender, operating time, tumor stage, and tumor differentiation.

\section{Disease-free survival}

Within the first 3 postoperative years, recurrence was detected in 23 cases of the ART group and 29 of the SYS group. Details of recurrent sites are shown in Table 2 . The 3 -year DFS did not differ between the 2 groups ( $p=0.0822$, hazard ratio $[\mathrm{HR}]=0.6270 ; 95 \% \mathrm{CI}, 0.3627$ to 1.0838 )

(Figure 1).

\section{Overall survival}

Within the first 3 postoperative years, 19 cases of the ART group and 26 of the SYS group died. The 3-year OS of the ART group was significantly higher than the SYS group ( $p=0.0378$, $\mathrm{HR}=0.5460 ; 95 \% \mathrm{CI}, 0.3025$ to 0.9856 ) (Figure 2).

Table I Patient characteristics

\begin{tabular}{|c|c|c|c|}
\hline Characteristic & $\begin{array}{l}\text { SYS group } \\
(n=39)\end{array}$ & $\begin{array}{l}\text { ART group } \\
(n=37)\end{array}$ & p-value \\
\hline Age (years) & $59.3 \pm 7.2$ & $58.6 \pm 6.8$ & 0.6647 \\
\hline Serum CA $19-9(\mathrm{U} / \mathrm{mL})$ & $475.4 \pm 45.6$ & $479.3 \pm 46.7$ & 0.7137 \\
\hline Tumor size $(\mathrm{cm})$ & $1.8 \pm 0.5$ & $2.0 \pm 0.6$ & 0.1179 \\
\hline Operating time (min) & I $18.6 \pm 29.3$ & $124.2 \pm 31.2$ & 0.4223 \\
\hline Blood loss during surgery (mL) & $475.2 \pm 48.7$ & $462.2 \pm 46.4$ & 0.2378 \\
\hline Gender & & & 0.4526 \\
\hline Male & 30 & 31 & \\
\hline Female & 9 & 6 & \\
\hline Tumor stage & & & 0.6633 \\
\hline II & 4 & 5 & \\
\hline IIla & 21 & 20 & \\
\hline Illb & 14 & 12 & \\
\hline Tumor differentiation & & & 0.8951 \\
\hline Well & 5 & 6 & \\
\hline Moderate & 14 & 12 & \\
\hline Poor & 20 & 19 & \\
\hline
\end{tabular}

Note: Data are presented as mean $\pm S D$ or number.

Abbreviations: ART group, 4 courses of intravenous chemotherapy following 2 courses of intra-arterial chemotherapy; CA, carbohydrate antigen; SYS group, 6 courses of intravenous chemotherapy. 
Table 2 Sites of recurrence

\begin{tabular}{llllll}
\hline & Local & Lung & Brain & Bone & Liver \\
\hline Sites of first recurrence & & & & & \\
$\quad$ ART group & 9 & 2 & 1 & 1 & 10 \\
$\quad$ SYS group & 8 & 1 & 1 & 2 & 17 \\
Sites of any recurrence & & & & & \\
$\quad$ ART group & 14 & 4 & 3 & 3 & 15 \\
SYS group & 13 & 3 & 2 & 2 & 22
\end{tabular}

Abbreviations: ART group, 4 courses of intravenous chemotherapy following 2 courses of intra-arterial chemotherapy; SYS group, 6 courses of intravenous chemotherapy.

\section{Hepatic metastases-free survival}

Within the first 3 postoperative years, 15 cases of the ART group and 22 of the SYS group developed hepatic metastases. The 3-year HMFS of the ART group was significantly higher than the SYS group $(p=0.0414, \mathrm{HR}=0.5187 ; 95 \% \mathrm{CI}, 0.2706$ to 0.9940 ) (Figure 3).

\section{Complication and toxicity}

Table 3 lists the chemotherapy toxicities of the 2 groups and no difference was found. All patients underwent 6 courses of chemotherapy. Hematoma of the femoral artery puncture site was documented in 4 cases of the ART group and was controlled by pressure dressing. All complication and toxicity was managed by conservative treatment.

\section{Discussion}

GBC is the most aggressive biliary tree cancer (BTC) and only radical resection can offer the chance for cure. ${ }^{10}$ Nevertheless, incidence of postoperative relapse is still high, even in patients with resectable GBC (stage 2-3) who received curative resection, including extensive lymph node dissection

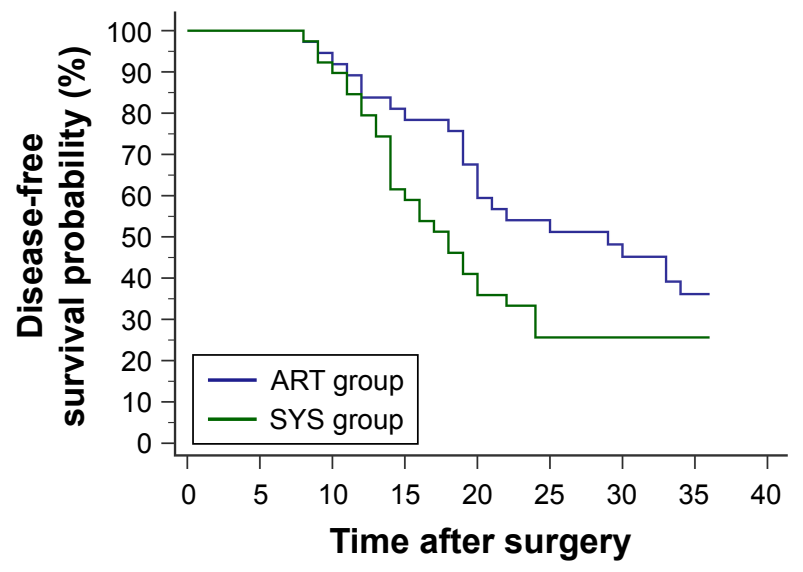

Figure I Within the first 3 postoperative years, 23 patients from the ART group ( 4 courses of intravenous chemotherapy following 2 courses of intra-arterial chemotherapy) and 29 patients from the SYS group (6 courses of intravenous chemotherapy) developed relapse or metastasis. No significant difference was found in the 3-year disease-free survival probability between the 2 groups $(p=0.0822$, $\mathrm{HR}=0.6270 ; 95 \% \mathrm{Cl}, 0.3627$ to $\mathrm{I} .0838)$.

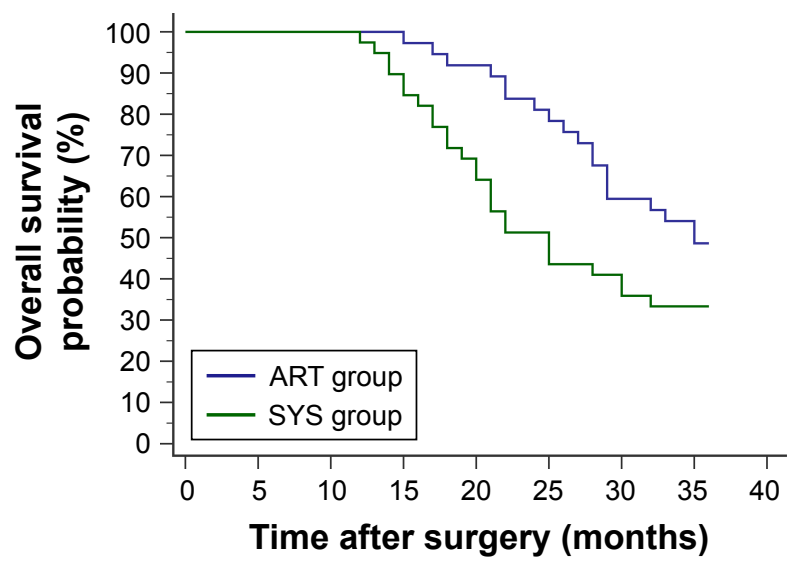

Figure 2 Within the first 3 postoperative years, 19 patients from the ART group ( 4 courses of intravenous chemotherapy following 2 courses of intra-arterial chemotherapy) and 26 patients from the SYS group (6 courses of intravenous chemotherapy) died. The ART group had a significantly higher 3-year overall survival probability than the SYS group ( $p=0.0378, \mathrm{HR}=0.5460 ; 95 \% \mathrm{Cl}, 0.3025$ to 0.9856 ).

and adjacent organ resection. ${ }^{1}$ The liver is the most common site of recurrence after radical resection of GBC. ${ }^{5}$ IAC is an effective treatment and prophylactic option for recurrence in the liver from primary carcinoma. ${ }^{6}$ Several studies demonstrated that IAC could offer significant survival benefit both in unresectable and resected GBCs. ${ }^{11-13}$ Moreover, IAC might be a safer and more effective adjuvant therapy strategy because administration of chemotherapy drugs via the hepatic arterial circulation can reach higher regional drug concentrations with lighter systemic toxicities than intravenous injection. ${ }^{14-16}$

Clinical trials were performed to investigate the survival benefit of different postoperative chemotherapy regimens for GBC. ${ }^{17,18}$ It was demonstrated that the 5-fluorouracil-based adjuvant chemotherapy offered no survival benefit for

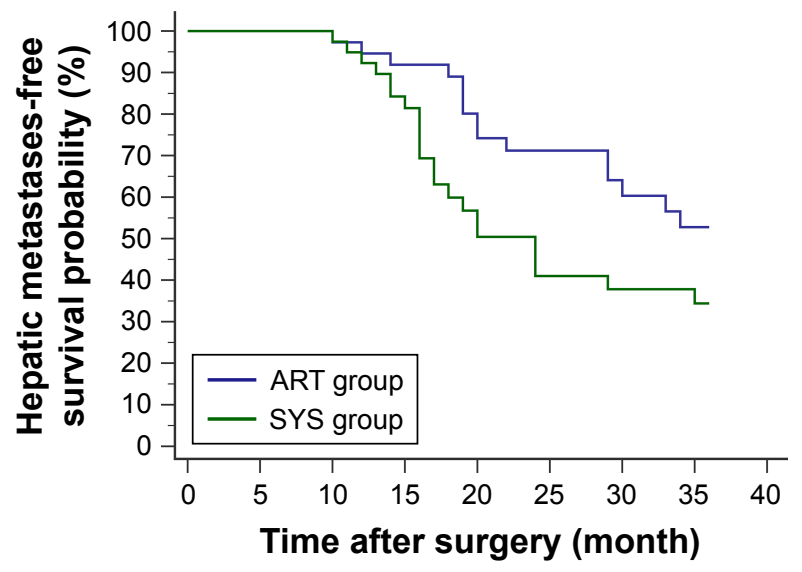

Figure 3 Within the first 3 postoperative years, hepatic metastases were reported in 15 patients from the ART group (4 courses of intravenous chemotherapy following 2 courses of intra-arterial chemotherapy) and 22 patients from the SYS group (6 courses of intravenous chemotherapy). Survival analysis showed a significantly higher 3-year hepatic metastases-free survival probability in the ART group compared with the SYS group ( $p=0.04 \mid 4, \mathrm{HR}=0.5 \mathrm{I} 87 ; 95 \% \mathrm{Cl}, 0.2706$ to 0.9940 ). 
Table 3 Toxicities

\begin{tabular}{|c|c|c|c|c|c|c|c|c|c|}
\hline \multirow[t]{3}{*}{ Adverse event } & \multirow{2}{*}{\multicolumn{4}{|c|}{$\frac{\text { SYS group }}{\text { Grade }}$}} & \multirow{2}{*}{\multicolumn{4}{|c|}{$\begin{array}{l}\text { ART group } \\
\text { Grade }\end{array}$}} & \multirow[t]{3}{*}{ p-valu } \\
\hline & & & & & & & & & \\
\hline & I & 2 & 3 & 4 & I & 2 & 3 & 4 & \\
\hline Neutropenia & 22 & 13 & 4 & 0 & 19 & 15 & 3 & 0 & 0.7615 \\
\hline Thrombocytopenia & 15 & 18 & 6 & 0 & 16 & 18 & 3 & 0 & 0.4815 \\
\hline Anemia & 16 & 19 & 4 & 0 & 15 & 17 & 5 & 0 & 0.8457 \\
\hline Nausea/vomiting & 15 & 17 & 7 & 0 & 13 & 18 & 6 & 0 & 0.8922 \\
\hline Diarrhea & 8 & 8 & 3 & 0 & 7 & 8 & 4 & 0 & 0.7153 \\
\hline Nephrotoxicity & 7 & 5 & 4 & 0 & 8 & 5 & 4 & 0 & 0.7200 \\
\hline Hepatic toxicity & 5 & 4 & 3 & 0 & 9 & 5 & 4 & 0 & 0.1535 \\
\hline Stomatitis & 10 & 6 & 4 & 0 & 8 & 7 & 3 & 0 & 0.8750 \\
\hline
\end{tabular}

Abbreviations: ART group, 4 courses of intravenous chemotherapy following 2 courses of intra-arterial chemotherapy; SYS group, 6 courses of intravenous chemotherapy.

resected GBC. ${ }^{19}$ A chemotherapy regime consisting of gemcitabine and oxaliplatin could offer a modest antitumor activity and is well tolerated in patients with biliary cancer including GBC. ${ }^{20}$ Due to the efficacy and safety of the gemcitabine and oxaliplatin chemotherapy regime, it was recognized as the first-line chemotherapy regime for BTCs. ${ }^{21}$ In the present study, we included resectable (stage 2-3) GBC patients and both the IAC and IVC regimens consisted of gemcitabine and oxaliplatin.

In the current study, the ART group had significantly higher 3-year OS and HMFS than the SYS group. However, the 3-year DFS did not differ, implying that the survival benefit of IAC may result from the decrease of hepatic metastases.

This study further verified the safety of the IAC regime. The comparison of toxicities showed no difference between the ART group and the SYS group. All of the patients tolerated 6 courses of chemotherapy and the toxicities were controllable.

\section{Conclusion}

IAC could effectively and safely decrease postresection hepatic metastases and improve 3-year HMFS and OS of stage 2-3 GBC. However, because of the limitation of the retrospective characteristic and single-center experience, prospective and multicenter studies are required to verify the results of the current study.

\section{Author contributions}

Cheng Chen and Min Feng designed the study and wrote the manuscript. Wenming Feng, Ying Bao, and Yinyuan Zheng collected and analyzed the data. All authors contributed toward data analysis, drafting and revising the paper and agree to be accountable for all aspects of the work.

\section{Disclosure}

The authors report no conflicts of interest in this work.

\section{References}

1. Mantripragada KC, Hamid F, Shafqat H, Olszewski AJ. Adjuvant therapy for resected gallbladder cancer: analysis of the National Cancer Data Base. J Natl Cancer Inst. 2016;109(2):pii: djw202.

2. Wang J, Narang AK, Sugar EA, et al. Evaluation of adjuvant radiation therapy for resected gallbladder carcinoma: a multi-institutional experience. Ann Surg Oncol. 2015;22 Suppl 3:S1100-S1106.

3. Aloia TA, Járufe N, Javle M, et al. Gallbladder cancer: expert consensus statement. HPB (Oxford). 2015;17(8):681-690.

4. Shukla SK, Singh G, Shahi KS, Bhuvan, Pant P. Staging, treatment, and future approaches of gallbladder carcinoma. J Gastrointest Cancer. 2018;49(1):9-15.

5. Margonis GA, Gani F, Buettner S, et al. Rates and patterns of recurrence after curative intent resection for gallbladder cancer: a multi-institution analysis from the US Extra-hepatic Biliary Malignancy Consortium. HPB (Oxford). 2016;18(11):872-878.

6. Wang Y, Sun XR, Feng WM, Bao Y, Zheng YY. Postoperative prophylactic hepatic arterial infusion chemotherapy for stage III colorectal cancer: a retrospective study. Onco Targets Ther. 2016;9:5897-5902.

7. Edge SB, Compton CC. The American Joint Committee on Cancer: the 7th edition of the AJCC cancer staging manual and the future of TNM. Ann Surg Oncol. 2010;17(6):1471-1474.

8. Kasugai H, Kojima J, Tatsuta M, et al. Treatment of hepatocellular carcinoma by transcatheter arterial embolization combined with intraarterial infusion of a mixture of cisplatin and ethiodized oil. Gastroenterology. 1989;97(4):965-971.

9. National Cancer Institute. Common Terminology Criteria for Adverse Events (CTCAE). Version 4.0. Rockville, MD: National Cancer Institute; 2009.

10. Duffy A, Capanu M, Abou-Alfa GK, et al. Gallbladder cancer (GBC): 10-year experience at Memorial Sloan-Kettering Cancer Centre (MSKCC). J Surg Oncol. 2008;98(7):485-489.

11. Nishimura M. A successful treatment by hepatic arterial infusion therapy for advanced, unresectable biliary tract cancer. World J Hepatol. 2010;2(5):192-197.

12. Nogita $H$, Uchida $S$, Ishikawa $H$, Hisaka $T$, Horiuchi $H$, Kinoshita $H$, Shirouzu K. [A long-term survivor of advanced gallbladder carcinoma treated with curative operation and hepatic arterial infusion]. Gan to Kagaku Ryoho. 2013;40(8):1081-1083. Japanese.

13. Bode MK, Perälä J, Mäkelä JT, Leinonen S. Intra-arterial chemotherapy with mitomycin C in gallbladder cancer: a follow-up study. J Surg Oncol. 2005;91(2):102-106.

14. Ackerman NB, Lien WM, Kondi ES, Silverman NA. The blood supply of experimental liver metastases. I. The distribution of hepatic artery and portal vein blood to "small" and "large" tumors. Surgery. 1969; 66(6):1067-1072

15. Conway JG, Popp JA, Ji S, Thurman RG. Effect of size on portal circulation of hepatic nodules from carcinogen-treated rats. Cancer Res. 1983;43(7):3374-3378.

16. Archer SG, Gray BN. Vascularization of small liver metastases. Br J Surg. 1989;76(6):545-548.

17. Park HS, Lim JY, Yoon DS, et al. Outcome of adjuvant therapy for gallbladder cancer. Oncology. 2010;79(3-4):168-173.

18. Choudhary S, Asthana AK. Impact of adjuvant therapy on survival in curatively resected gallbladder carcinoma. J Clin Diagn Res. 2015;9(9): $\mathrm{XC} 01-\mathrm{XC} 04$

19. de Aretxabala X, Roa I, Berrios M, et al. Chemoradiotherapy in gallbladder cancer. J Surg Oncol. 2006;93(8):699-704.

20. Jang JS, Lim HY, Hwang IG, et al. Gemcitabine and oxaliplatin in patients with unresectable biliary cancer including gall bladder cancer: a Korean Cancer Study Group phase II trial. Cancer Chemother Pharmacol. 2010;65(4):641-647.

21. Verderame F, Russo A, Di Leo R, et al. Gemcitabine and oxaliplatin combination chemotherapy in advanced biliary tract cancers. Ann Oncol. 2006;17 Supp1 7:vii68-vii72. 


\section{Publish your work in this journal}

OncoTargets and Therapy is an international, peer-reviewed, open access journal focusing on the pathological basis of all cancers, potential targets for therapy and treatment protocols employed to improve the management of cancer patients. The journal also focuses on the impact of management programs and new therapeutic agents and protocols on
Dovepress

patient perspectives such as quality of life, adherence and satisfaction. The manuscript management system is completely online and includes a very quick and fair peer-review system, which is all easy to use. Visit http://www.dovepress.com/testimonials.php to read real quotes from published authors.

\footnotetext{
Submit your manuscript here: http://www.dovepress.com/oncotargets-and-therapy-journal
} 